Lane, Sandi, Troyer, J.L, Dienemann. J.A., Laditka, S.B., Blanchette, C.M. (2014). Health Care Management Review. Vol. 39, no. 4, pp. 340-351. Copy of record available at: DOI: 10.1097/ HMR.0000000000000000

\title{
Effects of skilled nursing facility structure and process factors on medication errors during nursing home admission
}

\author{
Sandi J. Lane; Jennifer L. Troyer; Jacqueline A. Dienemann; \\ Sarah B. Laditka; Christopher M. Blanchette
}

\begin{abstract}
:
Background: Older adults are at greatest risk of medication errors during the transition period of the first 7 days after admission and readmission to a skilled nursing facility (SNF).

Purpose: The aim of this study was to evaluate structure- and process-related factors that contribute to medication errors and harm during transition periods at a SNF.

Methodology/Approach: Data for medication errors and potential medication errors during the 7day transition period for residents entering North Carolina SNFs were from the Medication Error Quality InitiativeVIndividual Error database from October 2006 to September 2007. The impact of SNF structure and process measures on the number of reported medication errors and harm from errors were examined using bivariate and multivariate model methods. Findings: A total of 138 SNFs reported 581 transition period medication errors; $73(12.6 \%)$ caused harm. Chain affiliation was associated with a reduction in the volume of errors during the transition period. One third of all reported transition errors occurred during the medication administration phase of the medication use process, where dose omissions were the most common type of error; however, dose omissions caused harm less often than wrong-dose errors did. Prescribing errors were much less common than administration errors but were much more likely to cause harm. Practice Implications: Both structure and process measures of quality were related to the volume of medication errors.
\end{abstract}


Older adults are especially susceptible to adverse drug events and medication errors due to frailty, multiple physical and cognitive ailments, complex

drug regimens, and frequent interactions with multiple health care providers. The National Coordinating Council for Medication Error Reporting and Prevention (NCCMERP; 2012) defines a medication error as "any preventable events that may cause or lead to inappropriate medication use or patient harm while the medication is in control of the health care professional, patient, or consumer" (paragraph 1). An adverse drug event (ADE) is a potential consequence of a medication error and is defined as "an injury resulting from the medical intervention related to a drug" (Bates et al., 1995, p. 30); an ADE may have resulted from "medication errors (i.e., errors in prescribing, dispensing, administration, and monitoring) or from adverse drug reactions in which no error was involved" (Gurwitz et al., 2000, p. 88). The Institute of Medicine (IOM) reported that medication errors contribute to 1.5 million ADEs annually (Aspenden, Wolcott, Bootman, \& Cronenwett, 2006). Approximately half of all ADEs requiring hospitalization were for individuals 65 years or older (Budnitz et al., 2006). For many older adults in skilled nursing facilities (SNFs), an ADE contributes to a downward cascade in health (Gurwitz et al., 2000).

Approximately 800,000 preventable ADEs occur in U.S. long-term care facilities annually, with an estimated 350,000 in SNFs (Gurwitz et al., 2005). In North Carolina, from 2005 to 2008, SNFs reported 12,993-16,106 medication errors and potential medication errors combined annually (circumstances or events that have the capacity to cause an error) (Hartwig, Denger, \& Schneider, 1991; Williams et al., 2008).

Studies of medication-related errors and ADEs in SNFs have found that residents are at greatest risk of medication errors during care transition periods such as admission and readmission to the nursing home after a hospitalization (Desai, Williams, Greene, Pierson, \& Hansen, 2011; Pronovost et al., 2003). Nearly half of all medication errors occur during transitions between levels of care or providers, a time when orders are frequently updated and changed (Bates et al., 1997). Medication errors during transitions are primarily due to poor communication between care teams (Aspenden et al., 2006). Understanding the medication use risk factors during transition into SNFs may improve safety during transitions and contribute to reductions in hospital readmissions. The Patient Protection and Afford- able Care Act encourages communication between providers and safer patient transitions through prohibiting reimbursement to hospitals for patients readmitted within 30 days. With many SNF residents admitted from hospitals, an improved understanding of medication use risk factors could be utilized to improve communication processes, reduce inaccurate documentation, and help to reduce hospital readmissions.

Although some research on the transition period for SNF residents is available, little is known about the interplay between errors and specific facility structure and process attributes that may contribute to the volume of errors and to harm from errors. The objective of this study was to identify structure and process quality measures that contribute to the number of medication errors reported and their harm during the transition period into SNFs.

\section{Background and Conceptual Framework}

Donabedian's (1966) frequently cited framework for analyzing quality in health care settings suggests that both structure and process measures may play a key role in explaining the occurrence of medication errors and the likelihood of harm from those errors.

Studies have evaluated relationships between structural variables such as ownership (Castle, 2000; Konetzka, Spector, \& Shaffer, 2004; O'Neill, Harrington, Kitchener, \& Saliba, 2003; Zinn, Spector, Hsieeh, \& Mukamel, 2005), chain membership (Castle, 2000; Konetzka et al., 2004; O'Neill et al., 2003; Zinn et al., 2005), size (Castle, 2000; O'Neill et al., 2003; Zinn et al., 2005), and location (Bowblis, Meng, \& Hyer, 2013; Hutchinson, Hawes, \& Williams 2005; Phillips, Holan, Sherman, Williams, \& Hawes, 2004) and quality-oriented outcomes, with varying results. Forprofit long-term care facilities were found to hospitalize their residents suspected of pneumonia 2 times more often than not-for-profit facilities (Konetzka et al., 2004), increase restraint use by 20\% (Castle, 2000), have 1.2 times more survey deficiencies, and have a higher total (25\%) number of F-plus survey deficiencies (O'Neill et al., 2003) (defined as potential or actual harm occurred for at least one resident) than not-for-profit facilities. Chain ownership was found to increase restraint use (31\% increase) (Castle, 2000) and number of survey deficiencies (Amirkhanyan, Kim, \& Lambright, 2008; O’Neill et al., 2003). Facility size produced 
varying effects in differences in outcomes. For example, restraint use decreased by $5 \%$ for every 10 -bed increase in nursing home size (Castle, 2000), whereas number of beds was not determined to contribute to higher numbers of deficiencies or F-plus deficiencies (O'Neill et al., 2003). Amirkhanyan et al. (2008) reported that as number of beds increased, for-profit facilities had significantly more deficiencies. Studies of facility location found nonurban nursing homes to have lower staffing ratios (Hutchinson et al., 2005) and more residents with acquired contractures (Bowblis et al., 2013) and higher risks of urinary tract infection and pressure ulcers (Phillips et al., 2004) than residents in urban nursing homes. Previous research on profit status and quality of resident care indicates that poorer quality of care occurs in for-profit SNFs (Castle \& Engberg, 2008; Intrator, Zinn, \& Mor, 2004). However, no study has considered the effect of these structure measures on the volume of selfreported medication errors and harm from medication errors during the 7-day transition into an SNF.

Research on the processes that have the largest impact on the volume of medication errors in SNFs considers a variety of processes and often includes studies of ADEs. For example, studies of medication use processes indicate that ADEs occurred most often during the monitoring phase and medication errors occurred most often during the administering phase of the process (Desai et al., 2011; Gurwitz et al., 2000, 2005; Williams et al., 2008). Studies of the types of errors vary with respect to the definitions used to categorize the error types. For example, studies defining wrong dose as overdose, underdose, or dose omission often report wrong dose as the most frequent type of error reported, ranging from $48 \%$ to $65 \%$ of the reported errors (Crespin et al., 2010; Desai et al., 2011; Gurwitz et al., 2005). In contrast, studies categorizing dose omission separately from overdose and underdose report that dose omissions occurred more frequently than wrong-dose errors (Barker, Flynn, Pepper, Bates, \& Mikeal, 2002; Williams et al., 2008). Research focusing on processes of care to assess medication errors reported during the 7 days of transition into the SNF is limited.

In addition to assessing the frequency of medication errors and processes contributing to the volume of errors, it is also useful to examine if harm occurred. One study of changes in medication orders for patients transitioning from a nursing home to a hospital and back to a nursing home reported that $8 \%$ of the bidirectional transfers experienced an $\mathrm{ADE}$ attributable to medication changes upon readmission to the SNF (Boockvar et al., 2004). Desai et al. (2011) examined medication errors during transition into the SNF and found that $1.5 \%$ of the errors occurring during the 7-day transition into the SNF caused harm, whereas harm occurred in only $0.7 \%$ of non-transitionperiod errors. We used a subset of the data that Desai et al. used in their study and focused only on those medication errors that were reported as occurring during transition. Our research extends their work and assesses the SNF structure and medication use process factors that could exacerbate the risk of harmful medication errors.

\section{Conceptual Framework}

On the basis of the previous nursing home research using the Donabedian framework, we hypothesized the following:

1) For-profit, larger, nonurban, chain-affiliated nursing homes will have a higher rate of medication errors during the 7 days after admission than will not-for-profit, smaller, urban, non-chain-affiliated nursing homes.

2) Medication errors in for-profit, larger, nonurban, and chain-affiliated nursing homes are more likely to be harmful than medication errors during the 7 days after admission in not-for-profit, smaller, urban, and non-chainaffiliated nursing homes.

3) Medication errors are more likely to be harmful during the 7 days after admission when administering is reported as the medication use phase compared with any other phase in the medication use process.

4) Medication errors are more likely to be harmful during the 7 days after admission when wrong dose is reported as the error type compared with any other type of error.

Hypotheses 1 and 2 consider the impact of the structure quality measures on the volume of medication errors and the probability of harm from a medication error. Hypotheses 3 and 4 consider the impact of process quality measures related to medication errors that might influence the probability that a resident is harmed when a medication error occurs. These include the phase of the drug delivery process in which the error occurs, the type of medication error, the underlying cause of the error, and the personnel involved in the error. In this study, type of medication error refers to the mistake made in the medication use process, whereas the phase of the medication use process refers to the timing of the error in the prescribing through postadministration phases of medication delivery. For example, "wrong dose" is a type of medication error where the correct medication is given to the correct resident at the correct time but in the wrong dose. A wrong-dose error may occur at several points in the medication use process; for instance, the wrong dose may occur due to a prescribing error or an administering error.

\section{Methods}

\section{Study Design and Data}

The Medication Error Quality Initiative (MEQI) data for North Carolina nursing homes was used. Medication Error Quality Initiative data are statutorily mandated self-reported medication errors and potential errors for all SNFs licensed 
in North Carolina. Reporting Year 4 (October 1, 2006September 30, 2007) provided the option to report errors using the individual error (IE) reporting or annual reporting system: 203 of the 393 SNFs opted to use the Webbased IE system (Williams et al., 2008). Crespin et al. (2010) indicate no evidence of differences in characteristics of errors reported by facilities using the aggregated annual system and those using the IE reporting system for reporting Year 4 in North Carolina. Because the focus of our study was the 7-day transition period, we included only those medication errors reported as occurring during the first 7 days of admission. The dataset contained only non-government-owned SNFs (i.e., not-for-profit and forprofit SNFs). Each facility in our dataset participated for the entire reporting year.

The MEQI-IE data allowed us to assess medication-errorrelated outcomes at the facility level (i.e., the number and type of medication errors by facility) and error report level (each reported medication error or potential medication error). The dichotomous variable indicating whether the resident was harmed by the medication error (1) or not (0) was constructed from the nine possible error impact categories established by NCC-MERP, of which six categories occur in the data during the 7-day transition period. The categories capacity to cause error (no resident involved; $1.2 \%$ of the errors during the 7 -day transition period), error did not reach resident $(7.8 \%)$, and error reached the resident but did not cause harm (78.5\%) were categorized as no harm. The categories of required monitoring/intervention to preclude harm $(10.3 \%$ of the errors during the 7-day transition period), temporary harm to resident $(1.6 \%)$, and temporary harm to resident with trip to emergency room $(0.7 \%)$ were categorized as causing harm. This categorization was also used by the Sheps Center researchers in preparing the annual MEQI reports.

Factors likely to affect outcomes include structure variables, process variables, and resident characteristics. Structure variables were ownership (for-profit, not-for-profit), size (number of beds), location (nonurban, urban), and whether the facility is part of a chain of nursing homes. Process variables were type of medication error, phase in the medication use process, personnel involved in the error, and the reported causes of the errors. In addition, the multivariate analysis of harm from an error included controls for resident characteristics as reported by the SNF in the MEQI-IE report; these included age, gender, whether residents were able to direct their own care, and number of medications taken per day.

We aggregated types of errors into seven categories to have sufficient numbers for meaningful analysis in each category: wrong patient, wrong drug, dose omission, wrong dose (referent), wrong administration, wrong follow-up, and other type of error. Phases in the medication use process were prescribing, dispensing, documenting, administering (referent), and monitoring. Possible causes of errors were also collapsed into the six categories of causes: product issues, recording issues, dispensing issues, facility issues, personnel issues, or other causes, where multiple causes may be present for each error. The MEQI-IE allows for multiple selections for reporting the possible causes or reasons for the error or potential error; therefore, the categories are not mutually exclusive. Personnel involved in the error were collapsed into two categories: licensed practical nurse (LPN) and all other non-LPN staff (e.g., registered nurses, medication aides, physicians, pharmacists, and so forth).

We acknowledge several limitations of our data use agreement: These data were limited to the first 7 days of admission and do not identify on which of the first 7 days the error occurred or where the resident was admitted from. We could not examine care transition periods of differing lengths, resident acuity, or whether the error was repeated.

\section{Data Analysis}

The dataset contained 581 errors reported by 138 SNFs during the 7 days after admission or readmission to an SNF from the 203 SNFs in the MEQI-IE database. One facility had an incorrectly coded variable, resulting in 137 SNFs used in the facility-level analysis, and seven reported errors had missing values for one or more resident characteristics, resulting in 574 observations used in the error-report-level analysis described below.

Two sets of results are presented. The first set of results considers the impact of SNF structure quality measures on the number of medication errors at the facility level. Descriptive statistics of the facility-level medication error counts over the 1 -year period were computed using the 138 facilities; next, medication error counts were modeled as a function of facility structural attributes for the 137 SNFs with complete data using negative binomial regression models. Two models were estimated; results are reported for models with and without an interaction between ownership type and chain affiliation. Incidence rate ratio (IRR) estimates for each structural explanatory variable are presented. The second set of results contains descriptive statistics based on all 581 medication errors, where bivariate tests for statistically significant differences in the proportion of errors causing harm were conducted. Given that it is likely that there are relationships among the various structural and process measures included as explanatory variables in our models, explanatory variables were assessed for multicollinearity by considering the variance inflation factor (VIF) for each independent variable using linear regression analysis; the VIF was found to be less than 2.5 in all cases. In a linear probability model, VIF values above 2.5 indicate likely multicollinearity (Allison, 1999). Next, two multivariate logistic regression models were estimated to examine the probability that a specific medication error was harmful using the 574 observations with complete data on resident characteristics. Model 1 includes all explanatory 
variables except the resident's number of medications for the 574 observations with complete data. Model 2 includes the number of medications; the 332 records with missing medications also had missing values for age, gender, and able to direct their own care observations, reducing the estimation sample from 581 to 249. Analyses were conducted using SAS Version 9.1 (Cary, NC).

\section{Findings}

\section{Facility-Level Analysis: Volume of Medication Errors}

As shown in Table 1, of the 203 SNFs that reported medication errors using the IE system (MEQI-IE), 138 $(67.9 \%)$ reported at least one medication error, and these reporting facilities had, on average, four errors during the first 7 days of a resident's admission. The average facility size was 120 beds, $62 \%$ of the facilities had 101 beds or more, $72 \%$ were for-profit, $68 \%$ were part of a chain, and $62 \%$ were located in an urban area.

Results of two negative binomial regression models of the number of medication error reports per facility are

\section{Table 1}

\section{Skilled nursing facility (SNF) 7-day transition error volume and structure factors}

\begin{tabular}{|c|c|c|}
\hline & \multicolumn{2}{|c|}{ Total } \\
\hline & $n$ & $\%$ \\
\hline Total SNFs & $137^{a}$ & 100 \\
\hline \multicolumn{3}{|l|}{ Ownership } \\
\hline Not-for-profit & 39 & 28.5 \\
\hline For-profit & 98 & 71.5 \\
\hline \multicolumn{3}{|l|}{ Affiliated with chain } \\
\hline No & 44 & 32.1 \\
\hline Yes & 93 & 67.9 \\
\hline \multicolumn{3}{|l|}{ Number of beds } \\
\hline$M(S D)$ & \multicolumn{2}{|c|}{$120(40.4)$} \\
\hline$<100$ & 51 & 37.0 \\
\hline $101-150$ & 60 & 43.5 \\
\hline$>151$ & 26 & 18.8 \\
\hline \multicolumn{3}{|l|}{ Facility location } \\
\hline Urban & 85 & 62.0 \\
\hline Nonurban & 52 & 38.0 \\
\hline Medication errors per SNF & \multicolumn{2}{|c|}{4.21} \\
\hline Medication errors per 100 beds & \multicolumn{2}{|c|}{3.59} \\
\hline
\end{tabular}

Note. Data source: North Carolina Medication Error Quality Initiative-Individual Error reporting system year 4, October 1, 2006-September 30, 2007.

${ }^{\mathrm{a}} \mathrm{An}$ error for one SNF reduced the analytical sample from 138 to 137 SNFs. presented in Table 2. Model 1 includes the binary indicators for ownership and chain affiliation as separate covariates. Model 2 includes interactions between ownership status and chain affiliation. In Model 1, the rate at which medication errors occurred for chain-affiliated SNFs was approximately two thirds the rate of medication errors found in non-chain-affiliated SNFs (IRR = 0.67; 95\% confidence interval [CI] [0.48, 0.92]). Model 2 shows that the rate at which medication errors occurred in chainaffiliated for-profit SNFs was less than the rate of errors in non-chain-affiliated for-profit SNFs (IRR $=0.68 ; 95 \% \mathrm{CI}$ $[0.45,1.01])$. In both models, SNFs with more than 151 beds had more than 2 times the rate of medication errors (Model 1, IRR $=2.12$; Model 2, IRR $=2.11$ ) found in SNFs with 100 beds or less.

\section{Medication Error Report Level: Harm From Medication Errors}

Descriptive statistics at the error level are shown in Table 3. During the 7-day transition period, 581 errors were reported, of which 73 (13\%) caused harm. Examining structure factors first, 405 (70\%) of the errors were reported by for-profit SNFs and 339 (58\%) were from chain-affiliated facilities; $61 \%$ of the reported errors were from SNFs located in an urban area; and nearly half of all errors were in facilities with 101-150 beds. In terms of process factors, the most commonly cited cause of errors was personnel issues (65\%), followed by recording issues (39\%). The most common types of medication errors were dose omission (36\%) and wrong dose (20\%). When considering the phase in the medication use process, errors occurred most often in the documenting phase (47\%), followed by errors in administration of medication (33\%). Only $4.8 \%$ of all errors in the transition period occurred in the prescribing phase. Finally, nearly two thirds of all errors involved an LPN. Turning to resident characteristics, residents experiencing medication errors were predominately women $(66 \%)$, had an average age of 78 years, were likely to be unable to direct their own care $(65 \%)$, and were taking an average of 12 medications.

For the binary variables, Table 3 shows the $p$ values for chi-square tests of significant differences in the proportion of errors causing harm. For continuous variables, $t$ tests examined differences between the mean values of harmful versus nonharmful medication errors. For structure factors, a statistically significant difference $(p \leq .05)$ in the proportion of errors causing harm is found only for facility location, where an error in an urban SNF is significantly more likely to be harmful than an error in a nonurban SNF. For process factors, there were no statistically significant differences in the probability of harm for each of the causes of errors and for the types of errors (with wrong dose as the reference category for the type of error). In the phases of the medication use process, although documenting errors represented $47 \%$ of all errors, they only represented $36 \%$ of 
Table 2

\section{Facility-level analysis of the number of medication errors reported during the 7 days of transition into the skilled nursing facility}

\begin{tabular}{|c|c|c|c|c|}
\hline \multirow[b]{2}{*}{ Variable/Category } & \multicolumn{2}{|l|}{ Model 1} & \multicolumn{2}{|l|}{ Model 2} \\
\hline & $\mathbf{I R R}^{\mathbf{a}}$ & $95 \% \mathrm{Cl}$ & IRR & $95 \% \mathrm{Cl}$ \\
\hline \multicolumn{5}{|l|}{ Ownership } \\
\hline For-profit & 1.12 & {$[0.80,1.59]$} & & \\
\hline \multicolumn{5}{|l|}{ Affiliated with a chain } \\
\hline \multicolumn{5}{|l|}{ No (ref) } \\
\hline Yes & $0.67 *$ & {$[0.48,0.92]$} & & \\
\hline \multicolumn{5}{|l|}{ Interaction } \\
\hline \multicolumn{5}{|l|}{ For-profit and not chain affiliated (ref) } \\
\hline Not-for-profit and chain affiliated & & & 0.59 & {$[0.33,1.04]$} \\
\hline For-profit and chain affiliated & & & 0.68 & {$[0.45,1.01]$} \\
\hline Not-for-profit and not chain affiliated & & & 0.91 & {$[0.55,1.48]$} \\
\hline \multicolumn{5}{|l|}{ Location } \\
\hline \multicolumn{5}{|l|}{ Nonurban (ref) } \\
\hline Urban & 0.97 & {$[0.73,1.30]$} & 0.97 & {$[0.73,1.30]$} \\
\hline \multicolumn{5}{|l|}{ Bed size } \\
\hline \multicolumn{5}{|l|}{$\leq 100$ (ref) } \\
\hline $101-150$ & $1.64 *$ & {$[1.18,2.26]$} & $1.64 *$ & {$[1.18,2.26]$} \\
\hline$\geq 151$ & $2.12 *$ & {$[1.44,3.13]$} & $2.11 *$ & {$[1.43,3.12]$} \\
\hline Number of observations & 137 & & 137 & \\
\hline \multicolumn{5}{|c|}{$\begin{array}{l}\text { Note. Data source: North Carolina Medication Error Quality Initiative-Individual Error reporting system, year 4, October 1, 2006-Septembe } \\
\text { 30, 2007. Model } 1 \text { includes no interaction between ownership and chain-affiliation. Model } 2 \text { includes an interaction between ownership and } \\
\text { chain-affiliation. IRR = incidence rate ratio; } \mathrm{Cl}=\text { confidence interval. }\end{array}$} \\
\hline \multicolumn{5}{|c|}{${ }^{2}$ Adjusted IRRs were estimated using negative binomial regression models. } \\
\hline${ }^{*} p<.05$ & & & & \\
\hline
\end{tabular}

harmful errors. In contrast, prescribing errors were overrepresented among harmful errors; they were only $4.8 \%$ of all errors but $18 \%$ of harmful errors. Errors involving LPNs were significantly less likely to cause harm than errors involving non-LPN staff. For resident characteristics, the average resident age was significantly lower for errors causing harm.

Table 4 shows the results of the multivariate analysis of the probability that a medication error caused harm. None of the structure factors were significant predictors of harm from a medication error. Of the process measures, none of the causes of errors were significant predictors of harm. In Model 1, which does not control for number of medications taken by a resident, the odds ratios (ORs) on all of the indicators for the type of error to cause harm were less than 1 , which suggests that the reference wrong-dose error is more likely to cause harm than other error types. For example, dose omission errors were less likely to cause harm $(\mathrm{OR}=0.45,95 \% \mathrm{CI}[0.23,0.89])$ than wrong-dose errors. When considering the phase in the medication use process in which the error occurred, in Model 1, the adjusted odds that a medication error was harmful were significantly higher for prescribing errors when compared with administering errors $(\mathrm{OR}=8.6,95 \% \mathrm{CI}[3.03,24.35])$. In Model 2, which controls for the number of medications taken by the resident, compared with wrong-dose errors, errors involving the wrong patient are less likely to cause harm $(\mathrm{OR}=0.09,95 \% \mathrm{CI}[0.01,0.71])$, whereas other types of errors are more likely to cause harm. Considering the phase of the medication use process, errors reported during the monitoring phase were less likely to cause harm than administering errors $(O R=0.34,95 \% \mathrm{CI}[0.13,0.94])$. Of the resident characteristics, age was statistically significant in Model 2, although only slightly greater than $1(O R=$ $1.06,95 \% \mathrm{CI}[1.01,1.10])$ of the probability of harm from a medication error.

\section{Discussion}

This study examined the facility-reported medication error reports for medication errors and potential medication errors that occurred during the 7-day transition period for residents entering or reentering an SNF, a time when 
Table 3

Error-level bivariate analysis of structure factors, process factors, and resident characteristics by whether a medication error caused harm

\begin{tabular}{|c|c|c|c|c|c|c|c|}
\hline & \multicolumn{2}{|c|}{ No harm } & \multicolumn{2}{|c|}{ Harm } & \multicolumn{2}{|l|}{ Total } & \multirow[b]{2}{*}{$p$} \\
\hline & $n$ & $\%$ or $M$ & $n$ & $\%$ or $M$ & $n$ & $\%$ or $M$ & \\
\hline \multicolumn{8}{|l|}{ Structure factors } \\
\hline \multicolumn{8}{|l|}{ Ownership } \\
\hline Not-for profit (ref) & 151 & $29.7 \%$ & 25 & $34.2 \%$ & 176 & $30.3 \%$ & \\
\hline For-profit & 357 & $70.3 \%$ & 48 & $65.8 \%$ & 405 & $69.7 \%$ & .43 \\
\hline \multicolumn{8}{|l|}{ Affiliated with chain } \\
\hline No (ref) & 209 & $41.1 \%$ & 33 & $45.2 \%$ & 242 & $41.7 \%$ & \\
\hline Yes & 299 & $58.9 \%$ & 40 & $54.8 \%$ & 339 & $58.3 \%$ & .51 \\
\hline \multicolumn{8}{|l|}{ Number of beds } \\
\hline$<100$ (ref) & 120 & $23.6 \%$ & 22 & $30.1 \%$ & 142 & $24.4 \%$ & \\
\hline $101-150$ & 250 & $49.2 \%$ & 33 & $45.2 \%$ & 283 & $48.7 \%$ & .27 \\
\hline$>151$ & 138 & $27.2 \%$ & 18 & $24.7 \%$ & 156 & $26.9 \%$ & .32 \\
\hline \multicolumn{8}{|l|}{ Facility location } \\
\hline Urban (ref) & 300 & $59.1 \%$ & 54 & $74.0 \%$ & 354 & $60.9 \%$ & \\
\hline Nonurban & 208 & $40.9 \%$ & 19 & $26.0 \%$ & 227 & $39.1 \%$ & .01 \\
\hline \multicolumn{8}{|l|}{ Process factors } \\
\hline \multicolumn{8}{|l|}{ Causes of errors ${ }^{a}$} \\
\hline Product issue & 24 & $4.7 \%$ & 5 & $6.8 \%$ & 29 & $4.99 \%$ & .44 \\
\hline Recording issue & 200 & $39.4 \%$ & 28 & $38.4 \%$ & 228 & $39.24 \%$ & .87 \\
\hline Dispensing & 54 & $10.6 \%$ & 7 & $9.6 \%$ & 61 & $10.50 \%$ & .79 \\
\hline Facility issue & 61 & $12.0 \%$ & 13 & $17.8 \%$ & 74 & $12.74 \%$ & .16 \\
\hline Personnel issue & 339 & $66.7 \%$ & 41 & $56.2 \%$ & 380 & $65.40 \%$ & .08 \\
\hline Other causes & 28 & $5.5 \%$ & 6 & $8.2 \%$ & 34 & $5.85 \%$ & .36 \\
\hline Total causes & 706 & & 100 & & 806 & & \\
\hline \multicolumn{8}{|l|}{ Types of medication errors } \\
\hline Wrong dose (ref) & 93 & $18.3 \%$ & 24 & $32.9 \%$ & 117 & $20.14 \%$ & \\
\hline Wrong patient & 17 & $3.3 \%$ & 4 & $5.5 \%$ & 21 & $3.61 \%$ & .36 \\
\hline Dose omission & 189 & $37.2 \%$ & 22 & $30.1 \%$ & 211 & $36.32 \%$ & .24 \\
\hline Wrong administration & 48 & $9.4 \%$ & 3 & $4.1 \%$ & 51 & $8.78 \%$ & .13 \\
\hline Wrong follow-up & 47 & $9.3 \%$ & 5 & $6.8 \%$ & 52 & $8.95 \%$ & .5 \\
\hline Other & 45 & $8.9 \%$ & 6 & $8.2 \%$ & 51 & $8.78 \%$ & .86 \\
\hline \multicolumn{8}{|l|}{ Medication use process } \\
\hline Administering (ref) & 172 & $33.9 \%$ & 22 & $30.1 \%$ & 194 & $33.4 \%$ & \\
\hline Prescribing & 15 & $3.0 \%$ & 13 & $17.8 \%$ & 28 & $4.8 \%$ & .00 \\
\hline Dispensing & 68 & $13.4 \%$ & 10 & $13.7 \%$ & 78 & $13.4 \%$ & .94 \\
\hline Documenting & 245 & $48.2 \%$ & 26 & $35.6 \%$ & 271 & $46.6 \%$ & .04 \\
\hline Monitoring & 8 & $1.6 \%$ & 2 & $2.7 \%$ & 10 & $1.7 \%$ & .47 \\
\hline \multicolumn{8}{|l|}{ Personnel involved } \\
\hline LPN & 334 & $65.7 \%$ & 39 & $53.4 \%$ & 373 & $64.2 \%$ & \\
\hline All other non-LPN (ref) & 174 & $34.3 \%$ & 34 & $46.6 \%$ & 208 & $35.8 \%$ & .04 \\
\hline \multicolumn{8}{|l|}{ Resident characteristics } \\
\hline Resident age ${ }^{\mathrm{b}}$ & 501 & 78.21 & 73 & 74.34 & 574 & 77.72 & .008 \\
\hline \multicolumn{8}{|l|}{ Resident qender ${ }^{\mathrm{b}}$} \\
\hline Male (ref) & 171 & $34.1 \%$ & 26 & $35.6 \%$ & 197 & $34.3 \%$ & \\
\hline \multirow{2}{*}{\multicolumn{8}{|c|}{ Resident able to direct own care ${ }^{\mathrm{b}}$}} \\
\hline & & & & & & & \\
\hline & 173 & $34.5 \%$ & 28 & $38.4 \%$ & 201 & $35.0 \%$ & \\
\hline No (ref) & 328 & $65.5 \%$ & 45 & $61.6 \%$ & 373 & $65.0 \%$ & .81 \\
\hline Number of medications ${ }^{c}$ & 218 & 12.01 & 31 & 12.29 & 249 & 12.05 & .74 \\
\hline Total number of errors & 508 & $87.4 \%$ & 73 & $12.6 \%$ & 581 & $100.0 \%$ & \\
\hline
\end{tabular}

Note. Data source: North Carolina Medication Error Quality Initiative-Individual Error reporting system, year 4, October 1, 2006-September 30, 2007. Chi-square tests for group differences in the proportion of errors that were harmful were conducted for each of the categorical variables. Similarly, $t$ tests were used for continuous measures. LPN = licensed practical nurse.

${ }^{a}$ Causes of errors are not mutually exclusive because selection of multiple causes was allowed.

${ }^{b}$ Data were missing for seven observations.

${ }^{\mathrm{c}}$ Number of medications is computed for residents with reported medications not missing and greater than zero. 
Table 4

Multivariate analysis of the probability that a medication error caused harm

\begin{tabular}{|c|c|c|c|c|}
\hline & \multirow{2}{*}{$\begin{array}{r}\text { Model } 1 \\
\text { Odds ratio }\end{array}$} & \multicolumn{3}{|c|}{ Model 2} \\
\hline & & $95 \% \mathrm{Cl}$ & Odds ratio & $95 \% \mathrm{Cl}$ \\
\hline \multicolumn{5}{|c|}{ Structure factors } \\
\hline \multicolumn{5}{|c|}{ Facility ownership (reference: NFP and not chain affiliated) } \\
\hline NFP and chain affiliated & 0.41 & {$[0.10,1.69]$} & 0.13 & {$[0.02,1.05]$} \\
\hline FP and not chain affiliated & 0.76 & {$[0.27,2.12]$} & 0.67 & {$[0.14,3.12]$} \\
\hline FP and chain affiliated & 1.02 & {$[0.50,2.06]$} & 0.76 & {$[0.23,2.51]$} \\
\hline \multicolumn{5}{|l|}{ Location (reference: urban) } \\
\hline Nonurban & 1.86 & {$[0.99,3.52]$} & 2.27 & {$[0.99,5.21]$} \\
\hline \multicolumn{5}{|c|}{ Number of beds (reference: $<100$ ) } \\
\hline $101-150$ & 0.69 & {$[0.38,1.24]$} & 1.19 & {$[0.45,3.16]$} \\
\hline$\geq 151$ & 0.49 & {$[0.23,1.03]$} & 1.04 & {$[0.28,3.88]$} \\
\hline \multicolumn{5}{|c|}{ Process factors } \\
\hline \multicolumn{5}{|c|}{ Causes of errors (reference: no cause reported) } \\
\hline Product issue & 1.42 & {$[0.48,4.15]$} & 0.21 & {$[0.03,1.38]$} \\
\hline Recording issue & 0.78 & {$[0.34,1.79]$} & 1.52 & {$[0.32,7.12]$} \\
\hline Dispensing & 0.51 & {$[0.21,1.23]$} & 0.53 & {$[0.12,2.39]$} \\
\hline Facility issue & 1.94 & {$[0.91,4.14]$} & 2.18 & {$[0.53,9.03]$} \\
\hline Personnel issue & 0.50 & {$[0.24,1.04]$} & 0.41 & {$[0.12,1.37]$} \\
\hline Other causes & 1.40 & {$[0.45,4.34]$} & 1.75 & {$[0.25,12.52]$} \\
\hline \multicolumn{5}{|c|}{ Type of medication error (reference: wrong dose) } \\
\hline Wrong patient & 0.74 & {$[0.20,2.80]$} & $0.09 *$ & {$[0.01,0.71]$} \\
\hline Wrong drug & 0.64 & {$[0.26,1.57]$} & 0.10 & {$[0.01,1.87]$} \\
\hline Dose omission & $0.45^{*}$ & {$[0.23,0.89]$} & 1.63 & {$[0.42,6.37]$} \\
\hline Wrong administration & 0.30 & {$[0.08,1.09]$} & 0.88 & {$[0.26,2.94]$} \\
\hline Wrong follow-up & 0.43 & {$[0.14,1.35]$} & 32.40 & {$[0.85,>999.99]$} \\
\hline Other type of error & 0.40 & {$[0.14,1.09]$} & $13.96 *$ & {$[1.92,101.68]$} \\
\hline \multicolumn{5}{|c|}{ Medication use process (reference: administering) } \\
\hline Dispensing & 1.20 & {$[0.47,3.08]$} & 3.34 & {$[0.15,73.85]$} \\
\hline Documenting & 0.97 & {$[0.47,2.01]$} & 1.72 & {$[0.47,6.34]$} \\
\hline Monitoring & 4.17 & {$[0.50,34.89]$} & $0.34^{*}$ & {$[0.13,0.94]$} \\
\hline Prescribing & $8.59 *$ & {$[3.03,24.35]$} & 0.13 & {$[0.01,2.16]$} \\
\hline \multicolumn{5}{|c|}{ Personnel involved (reference: LPN) } \\
\hline All other non-LPN & 0.68 & {$[0.39,1.20]$} & 2.02 & {$[0.69,5.91]$} \\
\hline \multicolumn{5}{|l|}{ Resident characteristics } \\
\hline \multicolumn{5}{|l|}{ Gender (reference: male) } \\
\hline Female & 0.84 & {$[0.49,1.46]$} & 0.43 & {$[0.15,1.24]$} \\
\hline Age & 0.98 & {$[0.96,1.00]$} & $1.06 *$ & {$[1.01,1.10]$} \\
\hline \multicolumn{5}{|c|}{ Patient able to direct own care (reference: able to direct own care) } \\
\hline No & 1.11 & {$[0.61,2.02]$} & 0.98 & {$[0.38,2.53]$} \\
\hline Number of medications & & & 1.02 & {$[0.93,1.13]$} \\
\hline Number of observations & 581 & & 249 & \\
\hline
\end{tabular}

Note. Data source: North Carolina Medication Error Quality Initiative_-Individual Error reporting system, year 4, October 1, 2006-September 30,2007 . We also estimated models without the interactions, and the resulting odds ratios were not statistically significant. Model 1 does not include number of medications, whereas Model 2 includes number of medications. All standard errors are adjusted for clustering within the skilled nursing facility. $\mathrm{Cl}=$ confidence interval; NFP = not-for-profit; FP = for-profit; LPN, licensed practical nurse.

${ }^{*} p \leq .05$.

medication orders are often updated to reflect the acuity level of the resident at the time of transfer. The first two hypotheses focused on structure-related medication errors. Regarding Hypothesis 1, our findings did not support any differences in errors for nonurban or for-profit facilities. As expected, we found that larger facilities have higher error rates. In addition, our results suggest that chain affiliation reduces the volume of errors during the 7-day transition period. Assuming equivalent statutory compliance in error reporting by chain-affiliated and non-chain-affiliated $\mathrm{SNF}$, this finding suggests that processes in chains may provide a protective effect against medication errors. 
Edmondson's (2004) work on organizational learning suggests that interpersonal climate and organizational culture can contribute to openness and willingness to discuss errors and near-misses; this may contribute to the differences in the reported errors between SNFs.

We did not find a difference in reported medication errors or harmful medication errors between urban SNFs and nonurban SNFs. This result could be attributable to the small sample size (581 errors), limited timeframe (1 year), and use of a dichotomous categorization for this variable. Bowblis et al. (2013) used four categories of location over a 10-year period and observed differences between urban and isolated SNFs in residents acquiring contractures. Kang, Meng, and Miller (2011) reported that residents in rural SNFs were 1.5 times more likely to be hospitalized after admission and have moderate or severe pain compared with residents in urban SNFs. With these factors and the lower staffing ratios reported in rural SNFs, differences between urban and nonurban SNF medication error reporting rates deserve further study.

Our findings differ from previous studies that found that chain affiliation contributed to poorer quality care (Amirkhanyan et al., 2008; Harrington, Woolhandler, Mullan, Carillo, \& Himmelstein, 2001). An alternative possibility that would support previous research would be that chain-affiliated facilities may have corporate cultures and policies that inadvertently create barriers to reporting medication errors through actions such as narrow interpretations of what defines a medication error, fear of legal liability, use of incident reports to monitor liability not improve patient care, or lack of a uniform standard for what kinds of errors are reported by SNFs (Barach, 2003; Mayo \& Duncan, 2004; Williams et al., 2011). These organizational cultures and corporate policies may lead to differences in the volume of error reports from non-chain-affiliated SNFs. Future research to better inform our understanding of chain affiliation and its impact on medication error reporting could be conducted with focus groups or structured interviews of nurses in chain-affiliated (both for-profit and not-for-profit) and non-chain-affiliated (both forprofit and not-for-profit) SNFs, examining barriers and enablers of reporting errors. Hypothesis 2 was also not supported. No significant relationships were found between the probability that an error caused harm and structure factors when controlling for process quality measures and resident characteristics.

The other two hypotheses focused on specific processes and medication errors. Hypothesis 3, focusing on administering medications, was not supported; however, we found a significant relationship between prescribing errors and harm. Prescribing errors made up less than $5 \%$ of all errors, yet these errors caused harm in nearly half of all occurrences. In the multivariate analysis, prescribing errors were 9 times more likely to cause harm during the transition period than were administering errors. This finding is consistent with previous studies (Desai et al., 2011; Gurwitz et al., 2000, 2005; Williams et al., 2008). Findings from the present study indicate that prescribing errors are the most pressing medication error problem for residents during the transition period into the SNF. Prescribing of medications often occurs during transition and thus contributes to its increased risk during this time. Causes of prescribing errors during transition are often attributable to transcription errors and poor communication.

Examining Hypothesis 4, we found wrong-dose errors to be more likely to be harmful than other types of medication errors. Findings from our study suggest that dose omission is the most likely medication error type during entry or reentry into the SNF, yet wrong dose contributed the most harm. These results are consistent with other studies (Boockvar et al., 2004; Desai et al., 2011; Leape et al., 1995). Factors contributing to wrong-dose errors include miscalculation of the dose or incomplete or illegible prescriptions (Gladstone, 1995; Wright, 2007). Dose omissions often have other causes, such as inaccurate medication history, unavailability of the drug, and errors in transcribing medication information during transfer (Lizer \& Brackbill, 2007; Pronovost et al., 2003). In our study, dose-omission errors were less harmful than wrong-dose errors.

Structure measures of ownership status, chain affiliation, number of beds, and location had no effect on the probability that a medication error caused harm. Given restrictions in the data use agreement, we considered only a limited number of structural attributes. It would be useful for future research to consider the impact of additional structure factors, such as nursing and pharmacy staffing levels, proportion of Medicaid residents, occupancy rates, and market factors. However, with that caveat in mind, our study suggests that the likelihood of harm from an error is more strongly related to process measures than structure measures of quality.

When interpreting findings from medication error analysis, it is important to discuss error reporting approaches, mandatory versus voluntary, which differ with respect to the perceived focus or use of the report. Using the Donabedian framework to describe incident reports, an outcomes-oriented approach describes an adverse event and the resultant harm (i.e., The National Quality Form's list of Serious Reportable Sentinel Events in Healthcare and The Joint Commission's Reviewable Sentinel Events), whereas a process-oriented approach encompasses nearmisses and variations in care with a perspective of systems improvement (i.e., MEDMARX is an Internet-based voluntary medication error reporting system). The IOM's 2011 report on health information technology and patient safety suggests that incident reports should be voluntary and used for system improvements and learning, not accountability or blame (Warden, 2011). Fear of reporting has been identified as a significant barrier in incident reporting in health care organizations, including nursing homes 
(Wagner, Castle, \& Handler, 2013). Very few studies report on medication errors from a mandatory error reporting system; exceptions using the North Carolina MEQI data are Desai et al., (2011), Crespin et al. (2010), and Williams et al. (2008). In contrast, Santell and Hicks (2005) used MEDMARX, the voluntary reporting system, in their studies of medication errors of hospitalized older adults.

Several study limitations should be considered when interpreting these findings. The data were self-reported from a mandatory reporting program in one state; compliance rates are not known. Without a nationwide mandatory reporting system, states have developed various adverse event reporting systems with little or no consistency between states. As of 2007, The National Academy for State Health Policy reported that 25 states and the District of Columbia had adverse event reporting systems. Lack of a national reporting strategy weakens the reporting consistency for nursing home organizations with SNFs in multiple states and clinicians who relocate to other states. Of the many methods available to document medication errors, selfreport of an error or near-miss has been shown to identify fewer errors than observation, which is a limitation of our study and others using self-reported errors. Facilities selfselected to report using the MEQI-IE Web-based reporting system. Although there is no evidence to suggest that the facilities differ from those using the annual reporting approach, it is possible that our nursing home sample is not representative of all North Carolina nursing homes in dimensions that matter for 7-day transition errors. The data are cross-sectional. It may be useful for future research to examine changes over time. Although we controlled for some resident characteristics in our analysis, resident characteristics such as disease burden and activity limitations were not available; their impact on the probability of harm from a medication error is not known. Finally, the MEQI data could not be merged with any other data, which limited the variables available for analysis.

\section{Practice Implications}

The findings from the present study indicate an opportunity to improve resident safety and outcomes during the transition period through implementation of continuous processes such as team-based approaches with shared responsibility, close communication with the consultant pharmacist and the care team, medication reconciliation, systematic monitoring process, and use of a standardized transfer form (LaMantia, Scheunemann, Viera, Busby-Whitehead, \& Hanson, 2010; Marcum, Handler, Wright, \& Hanlon, 2010; Steinman, Handler, Gurwitz, Schiff, \& Covinsky, 2011).

In addition, implementing systems such as computer provider order entry and electronic medical record systems may help to reduce harmful medication errors through changes in the ordering, administering, and monitoring processes. Effectiveness would be increased if the electronic systems had connectivity. Implementation of health information technology may improve adverse event reporting through anonymous reporting systems or, more importantly, an "adverse reporting system that is readily available" for staff use (Handler et al., 2007; Warden, 2011).

Collectively, the findings of the present study point to the importance of systems and policies to prevent medication errors during the transition into the SNF, such as careful transcription, medication reconciliation, pharmacists monitoring the appropriateness of and interactions between medications, and communication between hospitals and nursing homes at the time of transfer (Shah, Burack, \& Boockvar, 2009).

\section{Conclusions}

Our study finding of a lower volume of errors in chainaffiliated SNFs suggest that the processes and mechanisms utilized by these systems for medication error identification, reporting, and reduction may differ from independent facilities. Potential examples of process variations that may be related to chain affiliation include training mandates, nurse staffing levels, standardized medication review systems, risk management reviews resulting in practice changes, and error reporting cultures.

When examining individual errors, we found that the probability that an error causes harm during the 7-day transition period was unrelated to structure factors and resident characteristics but was related to several different process-related quality measures. These findings support the need for preventive processes to avoid harm such as administrative controls and barriers, communication between care teams, computer provider order entry and electronic medical record systems, and physician and pharmacy review.

\section{Acknowledgments}

The authors acknowledge the Sheps Center for Health Services Research at the University of North Carolina at Chapel Hill for the data. The authors also thank Dr. L. Michele Issel and three anonymous reviewers for their suggestions on an earlier version of this manuscript.

\section{References}

Allison, P. A. (1999). Logistic regression using the SAS system. Cary, NC: SAS Institute.

Amirkhanyan, A. A., Kim, H. J., \& Lambright, K. T. (2008). Does public sector outperform the nonprofit and for-profit sectors? Evidence from a National Panel Study on Nursing 
Home Quality and Access. Journal of Policy Analysis and Management, 27(2), 326-353.

Aspenden, P., Wolcott, J., Bootman, J., \& Cronenwett, L. (Eds.). (2006). Preventing medication errors. Washington, DC: National Academy Press.

Barach, P. (2003). The end of the beginning: Lessons learned from the Patient Safety Movement. Journal of Legal Medicine, 24(1), 7-27.

Barker, K. N., Flynn, E. A., Pepper, G. A., Bates, D. W., \& Mikeal, R. L. (2002). Medication errors observed in 36 health care facilities. Archives of Internal Medicine, 162, 1897-1903.

Bates, D. W., Cullen, D. J., Laird, N., Petersen, L. A., Small, S. D. Servi, D., ... Leape, L. L., (1995). Incidence of adverse drug events and potential adverse drug events: Implications for prevention. Journal of the American Medical Association, 274(1), 29-34.

Bates, D. W., Spell, N., Cullen, D., Burdick, E., Laird, N., Petersen, L., ... Leape, L. L. (1997). The costs of adverse drug events in hospitalized patients. Journal of the American Medical Association, 277(4), 307-311.

Boockvar, K. S., Fishman, E., Kyriacou, C., Monias, A., Gavi, S., \& Cortes, T. (2004). Adverse events due to discontinuations in drug use and dose changes in patients transferred between acute and long-term care facilities. Archives of Internal Medicine, 164(5), 545-550.

Bowblis, J. R., Meng, M., \& Hyer, K. (2013). The urban-rural disparity in nursing home quality indicators: The case of facilityacquired contractures. Health Services Research, 48(1), 47-69.

Budnitz, D., Pollock, D., Weidenback, K., Mendelsohn, A., Schroeder, T., \& Annest, J. (2006). National surveillance of emergency department visits for outpatient adverse drug events. Journal of the American Medical Association, 296(15), 1858-1866.

Castle, N. (2000). Differences in nursing homes with increasing and decreasing use of physical restraints. Medical Care, 38(12), 1154-1163.

Castle, N., \& Engberg, J. (2008). Further examination of the influence of caregiver staffing levels on nursing home quality. Gerontologist, 48, 464-476.

Crespin, D. J., Modi, A. V., Wei, D., Williams, C. E., Greene, S. B., Pierson, S., Hansen, R. A. (2010). Repeat medication errors in nursing homes: Contributing factors and their association with patient harm. The American Journal of Geriatric Pharmacotherapy, 8(3), 258-270.

Desai, R., Williams, C. E., Greene, S. B., Pierson, S., \& Hansen, R. A. (2011). Medication errors during patient transitions into nursing homes: Characteristics and association with patient harm. The American Journal of Geriatric Pharmacotherapy, 9(6), 413-422.

Donabedian, A. (1966). Evaluating the quality of medical care. Milbank Memorial Fund Quarterly, 44(3), 166-203.

Edmondson, A. C. (2004). Learning from failure in health care: Frequent opportunities, pervasive barriers. Quality 8 Safety in Health Care, 13(Suppl. II), ii3-ii9.

Gladstone, J. (1995). Drug administration errors: A study into the factors underlying the occurrence and reporting of drug errors in a district general hospital. Journal of Advanced Nursing, 22(4), 628-637.

Gurwitz, J. H., Field, T. S., Avorn, J., McCormick, D., Jain, S., Eckler, M., ... Bates, D. W. (2000). Incidence and preventability of adverse drug events in nursing homes. The American Journal of Medicine, 109, 87-94.
Gurwitz, J. H., Field, T. S., Judge, J., Rochon, P., Harrold, L., Cordet, M., ... Bates, D. W. (2005). The incidence of adverse drug events in two large academic long-term care facilities. The American Journal of Medicine, 118(3), 251-258.

Handler, S. M., Perera, A., Olshansky, E. F., Studenski, S. A., Nace, D. A., Fridsma, D. B., Hanlon, J. T. (2007). Identifying modifiable barriers to medication error reporting in the nursing home setting. Journal of the American Medical Directors Association, 8(9), 568-574.

Harrington, C., Woolhandler, S., Mullan, J., Carillo, H., \& Himmelstein, D. U. (2001). Does investor ownership of nursing homes compromise the quality of care? American Journal of Public Health, 91(9), 1452-1455.

Hartwig, S., Denger, S., \& Schneider, P. (1991). Severityindexed, incident report-based medication error-reporting program. American Journal of Hospital Pharmacy, 48, 2611-2616.

Hutchinson, L., Hawes, C., \& Williams, L. (2005). Access to quality health services in rural areas-Access to long-term care. In L. Gamm \& L. Hutchison (Eds.), Rural healthy people 2010: A companion document to healthy people 2010 (Vol. 3, pp. 5-30). Retrieved January 15, 2013, from http:// srph.tamhsc.edu/centers/rhp2010/litrev.htm

Intrator, O., Zinn, J., \& Mor, V. (2004). Nursing home characteristics and potentially preventable hospitalizations of long-stay residents. Journal of the American Geriatric Society, 52(10), 1730-1736.

Kang, Y., Meng, M., Miller, N. A. (2011). Rurality and nursing home quality: Evidence from the 2004 National Nursing Home Survey. Gerontologist, 51(6), 761-773.

Konetzka R, Spector, W, \& Shaffer, T. (2004). Effects of nursing home ownership type and resident payer source on hospitalization for suspected pneumonia. Medical Care, 42(10):1001-1008.

LaMantia, M. A., Scheunemann, L. P., Viera, A. J., BusbyWhitehead, J., \& Hanson, L. C. (2010). Intervention to improve transitional care between nursing homes and hospitals: A systematic review. Journal of the American Geriatric Society, 58(4), 777-782.

Leape, L. L., Bates, D. W., Cullen, D. J., Cooper, J., Demonaco, H. J., Gallivan, T., ... Vander Vliet, M. (1995). Systems analysis of adverse drug events. Ade Prevention Study Group. Journal of the American Medical Association, 274(1), $35-43$.

Lizer, M., \& Brackbill, M. (2007). Medication reconciliation by pharmacists in an inpatient behavioural health unit. American Journal of Health System Pharmacy, 64, 1087-1091.

Marcum, Z. A., Handler, S. M., Wright, R., \& Hanlon, J. T. (2010). Interventions to improve suboptimal prescribing in nursing homes: A narrative review. American Journal of Geriatric Pharmacotherapy, 8(3), 183-200.

Mayo, A., \& Duncan, D. (2004). Nurse perceptions of medication errors: What we need to know for patient safety. Journal of Nursing Care Quality, 19(3), 209-217.

National Coordinating Council for Medication Error Reporting and Prevention. (2012). About Medication Errors. Retrieved June 25, 2012, from http://www.nccmerp.org/ aboutMedErrors.html

O’Neill, C., Harrington, C., Kitchener, M., \& Saliba, D. (2003). Quality of care in nursing homes an analysis of relationships among profit, quality, and ownership. Medical Care, 41(12), 1318-1330. 
Phillips, C. D., Holan, S., Sherman, M., Williams, M. L., Hawes, C. (2004). Rurality and nursing home quality: Results from a national sample of nursing home admissions. American Journal of Public Health, 94(10), 1717-1722.

Pronovost, P., Weast, B., Schwarz, M., Wyskiel, R. M., Prow, D., Milanovich, S. N., ... Lipsett, P. (2003). Medication reconciliation: A practical tool to reduce the risk of medication errors. Journal of Critical Care, 18(4), 201-205.

Santell, J. P., \& Hicks, R. W. (2005). Medication errors involving geriatric patients. Joint Commission Journal on Quality and Patient Safety, 31(4), 233-238.

Shah, F., Burack, M. A., \& Boockvar, K. S. (2009). Perceived barriers to communication between hospital and nursing home at time of patient transfer. Journal of the American Medical Directors Association, 11(4), 239-245.

Steinman, M. A., Handler, S. M., Gurwitz, J. H., Schiff, G. D., $\&$ Covinsky, K. E. (2011). Beyond the prescription: Medication monitoring and adverse drug events in older adults. Journal of the American Geriatric Society, 59(8), 1513-1520.

Wagner, L. M., Castle, N. G., \& Handler, J. M. (2013). Use of
HIT for adverse event reporting in nursing homes: Barriers and facilitators. Geriatric Nursing, 34(2), 112-115.

Warden, G. (2011). Health IT for patient safety: Building safer systems for better care. Washington, DC: National Academy Press.

Williams, C. E., Greene, S. B., Hansen, R. A., Pierson, S., Akers, R., Caprio, A., \& Desai, R. (2011). Nursing Home Medication Error Quality Initiative (MEQI), annual report FY2011, October 1, 2010 to September 30, 2011. Chapel Hill, NC: The Cecil G. Sheps Center for Health Services Research at the University of North Carolina at Chapel Hill.

Williams, C. E., Greene, S. B., Hansen, R. A., Pierson, S., Akers, R., $\&$ Carey, T. (2008). Nursing Home Medication Error Quality Initiative, MEQI report: Year four, October 1, 2006 to September 30, 2007. Chapel Hill, NC: The Cecil G. Sheps Center for Health Services Research at the University of North Carolina at Chapel Hill.

Wright, K. (2007). Student nurses need more math to improve their drug calculating skills. Nurse Education Today, 27, 278-285.

Zinn, J. S., Spector, W., Hsieeh, L., \& Mukamel, D. (2005). Do trends in reporting of quality measures on the Nursing Home Compare Web Site differ by nursing home characteristics? Gerontologist, 45(6), 720-730. 